\title{
EXPLORING L1 TRANSFER IN GERMAN LEARNERS OF ENGLISH: High FRONT VOWELS, HiGH BACK VOWELS AND THE BED/BAD DISTINCTION
}

\author{
ALEXANDER KAUTZSCH \\ alexander.kautzsch@sprachlit.uni-regensburg.de \\ University of Regensburg
}

\begin{abstract}
Since the vowel systems of German and English are similar to some extent, German learners of English can be expected to transfer a considerable part of their German vowels to their L2 English. This paper traces the extent and source of positive and negative L1 transfer in two groups of university students from different German L1 backgrounds. To this end, acoustical analyses of three areas of vowel space are provided: high front vowels, high back vowels and $\mathrm{mid} / \mathrm{low}$ front vowels. While positive transfer widely persists with high front vowels, learners refrain from consistently transferring high back vowels, probably owing to variability both in L1 German and in L2 English. In the case of $\mathrm{mid} /$ low front vowels negative transfer is reduced due to exposure to native English, and even more so due to formal instruction, which appears to accelerate the acquisition process
\end{abstract}

Key words: L1 transfer English/German, vowels, acoustic analyses, L2 acquisition, phonology

\section{Introduction}

The study of learner English has become a thriving field in three areas of linguistics that overlap to some extent: "World Englishes", "English as a Lingua Franca", and "Second Language Acquisition".

From the "World Englishes" perspective, learner English can either be treated as a second language variety (ESL) or as a foreign language variety (EFL). Along these lines, ESL and EFL correspond to the outer or the expanding circle of Kachru's (1986, 1990) three-circle model of Englishes.

"English as a Lingua Franca" does not focus on the description of separate varieties of learner English and the role of English in the respective community, but rather on establishing variety status for the type of English used among non-native speakers of different first language (L1) backgrounds. This is pursued by identifying systematic similarities across learner Englishes. (cf. Jenkins 2007; Seidlhofer 2007). 
In the present paper, learner English is analysed within the framework of "Second Language Acquisition" (SLA) ${ }^{1}$, which studies the details of the learners' acquisition process on all linguistic levels. The study analyses the acquisition of English vowels by German university students of English and interprets the findings in the light of positive and negative L1 transfer. To that end, German and English vowels produced by these learners are analysed acoustically, with the accompanying vowel plots for both L1 and L2 sounds providing a solid basis for the visualization of transfer processes.

The results imply that the pronunciation of vowels in L2 English mainly originates from positive and sometimes negative transfer. However, in places where transfer would indeed be possible some of the participants do not transfer L1 sounds but produce L2 target-like vowels. To account for this, the results of the analyses are correlated with the following variables: the speakers' regional L1 background, their proficiency level, their time spent in an English-speaking country, their motivation to sound different from their $\mathrm{L} 1$, and the type of language instruction at their universities.

\section{German/English vowel contrasts and the Notion of Transfer}

The present chapter will first briefly summarize the notion of transfer in SLA and will then give a survey of the vowel systems of English and German in order to identify where transfer from L1 to L2 can be expected.

\subsection{Transfer in SLA}

Starting in the $1950 \mathrm{~s}$, L1 transfer was originally used to account for pronunciation problems in the L2 within the framework of the Contrastive Analysis Hypothesis (CAH) (e.g. Lado 1957). This approach was closely connected to behaviourist theory and assumed that in acquiring an L2, learners had to form a set of habits. Transfer was thus seen as a process in which learners take over habits from their L1 to an L2. If the two languages are similar and the habits of the L1 are appropriate in the L2, transfer was said to be positive. Taking over inappropriate habits from L1 to L2 was termed negative transfer. Thus, similarity was assumed to correlate with simplicity and difference with difficulty. (cf. Gut 2009:21-22, Jenkins 2000:99-100)

Due to its behaviourist roots and the low level of predictability about the route of acquisition, the concept of transfer fell into disrepute. But it has been welcomed back as a major factor in SLA and is again seen as highly relevant (Jenkins 2000:100, Gut 2009:21). This is, for example, due to Eckman's (1977) "Markedness Differential Hypothesis", in which he tries to predict areas of difficulty in SLA on the basis of typological differences between L1 and L2.

\footnotetext{
${ }^{1}$ Strictly speaking, a distinction can be made between Foreign Language Acquisition and Second Language Acquisition. The two terms then relate to tutored as opposed to untutored acquisition, respectively. But it is far from clear whether acquisition in these contexts works in different way. This is why Second Language Acquisition is mostly used as a cover term for both. (cf. Ellis 1985:5)
} 
Another aspect that stresses the importance and in fact unavoidability of transfer in SLA is that, from a cognitive point of view, transfer is a universal principle: prior knowledge is applied in new contexts (cf. Schachter 1983). This is especially true in L2 pronunciation, where

$[\mathrm{M}]$ any features of the L2 phonology, while different from those of the L1, particularly at the phonetic level, are instinctively categorizable within the L1 system and possible to approximate in varying degrees of closeness to the L2. (Jenkins 2000:104).

Along these lines, it also becomes apparent why, despite some behaviourist connotations, "certain types of phonetic transfer" can be viewed in the light of "habit formation" (Odlin 1989:116). The production of speech sounds first and foremost involves motor skills of the speech organs, which are applied automatically to produce L1 sounds, and which can easily be seen as habits. The learner will then automatically transfer these habits into L2 "if a sound [...] in L1 also occurs in L2" (Major 1987:106).

This, finally, leads to the problem of identifying an L2 sound as similar or identical to an L1 sound. Flege and Hillenbrand (1984:177) state that "judging acoustically different phones to be members of the same [phoneme] is a fundamental aspect of human speech perception". In this context, a learner will only refrain from transferring his or her L1 habit to the L2 when the phonetic difference is perceived. An example for this would be native speakers of Italian using [i] in English when [I] would be more appropriate. Thus, in cases involving a high amount of phonetic detail, the original notion of "similarity equals simplicity" in SLA is reversed (Jenkins 2000:114).

\subsection{The vowel systems of German and English}

Figure 2-1 (figure V.3 from Kortmann 2005:184) contrasts the vowel systems of English and German ${ }^{2}$. The ellipses in the figure enclose the vowels that are phonetically similar in English and German. Since similar features are frequently transferred from L1 to L2 in the acquisition process, it is likely that German learners of English transfer at least some of their German vowels to L2 English.

The present study focuses on three groups of similar vowels: high front vowels (English and German /I/ and /i:/), high back vowels (English and German / / / and /u:/), and short mid front vowels (English /e/, German $/ \varepsilon /)^{3}$.

\footnotetext{
${ }^{2}$ Even if the present study will use acoustic representations in the results section (4.), an articulatory vowel quadrilateral is instructive at this point to get a first grasp on the differences between the two systems, especially since acoustic representations are usually plotted on inverted F1/F2 graphs as to resemble articulatory representations. (Thanks to an anonymous reviewer for hinting at this discrepancy.)

${ }^{3}$ The remaining vowel pairs $/ \mathrm{N} /-/ \mathrm{a} /, / \mathrm{p} /-/ \mathrm{o} /, / \mathrm{a}: /-/ \mathrm{a}: /$, and $/ \mathrm{o}: /-/ \mathrm{o}: /$ will have to be treated elsewhere (Kautzsch, in preparation a).
} 


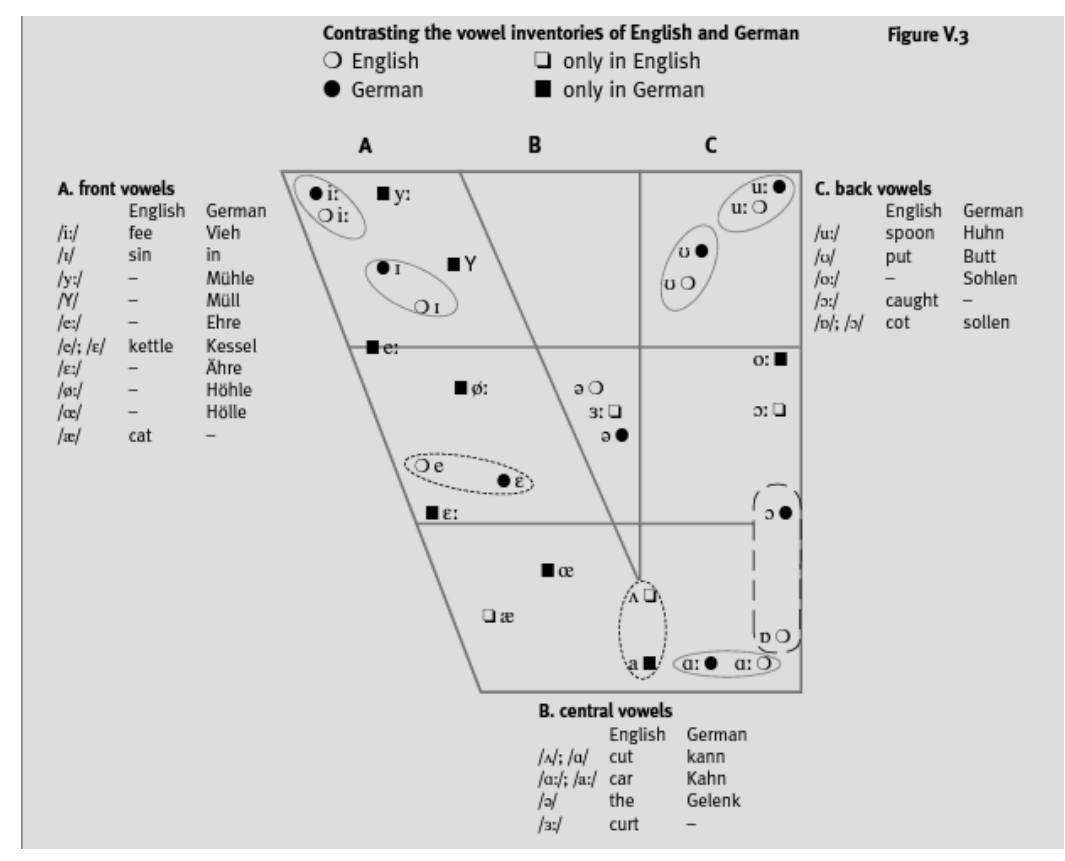

Figure 2-1: English-German vowel contrasts (Kortmann 2005:184)

In the first two groups positive transfer can be expected, because transferring the German sounds to English will result in appropriate pronunciation. In the third group the situation is more complicated. Figure 2-1 contains only English /e/ and German / $\mathcal{E} /$ as similar sounds. But in a comprehensive analysis of transfer of mid front vowels from German to English the two German long mid front vowels /e:/ and / $\varepsilon$ :/ need to be included, as well as English /æ/, the low front vowel that German learners frequently find difficult to acquire and to distinguish from /e/. Thus, in terms of transfer, learners have the following three options in this group: First, they might not perceive the difference between English /e/ and /æ/ and use German / $/$ / in both contexts. In this case, positive transfer takes place when learners use German $/ \varepsilon /$ for English /e/, negative transfer takes place when learners use German $/ \varepsilon /$ for English $/ æ /$. As a result, the distinction between $/ \mathrm{e} /$ and $/ \mathfrak{m} /$ is given up. Alternatively, learners may transfer the qualities of the German long mid vowels /e:/ and / $\varepsilon: /$ and use /e/ and /e/ instead of the English short vowels /e/ and /æ/. Here, positive transfer would be at work because /e/ and $/ \varepsilon /$ are an acceptable substitute for $/ \mathrm{e} /$ and $/ æ /$. As a third option learners use the German short mid front $/ \varepsilon /$ in /e/-contexts (which is again positive transfer) and acquire a phonetically new short mid low vowel /æ/. 


\section{Data}

\subsection{Informants}

This study analyses 40 university students of English recorded at the universities of Cologne and Regensburg (cf. table 3-1) ${ }^{4}$. All participants had a minimum of seven years of instruction at school and a variety of language classes at their respective universities. The learners are subdivided into their proficiency levels as beginners and advanced students. The twenty "beginners" are in their first or second year at university, while the twenty "advanced students" are in their third year or later.

Table 3-1: Survey of informants

\begin{tabular}{|l|l|l|l|l|l|}
\hline $\begin{array}{l}\text { Number of } \\
\text { informants }\end{array}$ & Region & Proficiency & Sex & $\begin{array}{l}\text { Reported } \\
\text { variety }\end{array}$ & $\begin{array}{l}\text { Overall time spent } \\
\text { abroad }\end{array}$ \\
\hline 10 & Bavaria & advanced & $6 \mathrm{f}, 4 \mathrm{~m}$ & 5BrE, 5AmE & 9 years \\
\hline 10 & Bavaria & beginners & $5 \mathrm{f}, 5 \mathrm{~m}$ & 5BrE, 5AmE & $\begin{array}{l}\text { 2 years 2 months } \\
\text { 8 months (excl. } \\
\text { one speaker) }\end{array}$ \\
\hline 10 & Non-Bavaria & advanced & $6 \mathrm{f}, 4 \mathrm{~m}$ & $\begin{array}{l}\text { 3BrE, 3AmE, } \\
\text { 4mix years 4 months }\end{array}$ \\
\hline 10 & Non-Bavaria & beginners & $6 \mathrm{f}, 4 \mathrm{~m}$ & $\begin{array}{l}\text { 4BrE, 3AmE, } \\
\text { 1Aus, 2mix }\end{array}$ & 4 years 10 months \\
\hline
\end{tabular}

In addition, the informants come from different L1 regions of Germany, twenty of them from Bavaria in the south of Germany and twenty from outside Bavaria (henceforth called "non-Bavarian" ). Of the latter twenty, in turn, 14 (i.e. all advanced students and four of the beginners) were born and raised in North Rhine-Westphalia in the western part of Germany (cf. Map 3-1) ${ }^{6}$.

\footnotetext{
${ }^{4}$ Many thanks go to the students who have taken part in this study. The students from Regensburg are volunteers from some of my own classes. In Cologne, my colleagues Beate Abel, Chris Bongartz, Sarah Buschfeld, and Christiane Schöneberger established contact for me with their students, for which I am also most grateful.

${ }^{5}$ This term is not intended to sound Bavaria-centric, but only labels the informants in a most economical way.

${ }^{6}$ At the time of analysis only four of the students recorded in the "non-Bavarian beginners" group came from North Rhine-Westphalia. This is why six students were taken from outside Bavaria and North Rhine-Westphalia (two from Baden-Württemberg, two from Niedersachsen, and one each from Schleswig-Holstein and Brandenburg) to have a representative amount of data available.
} 


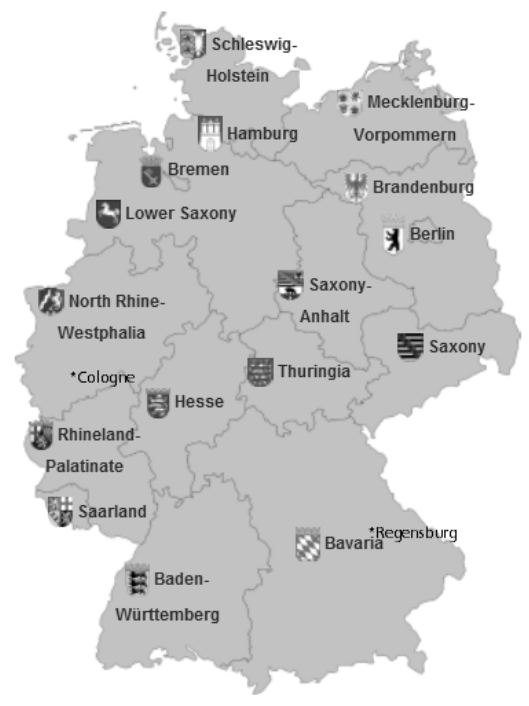

Map 3-1: Map of Germany (http://en.wikipedia.org/wiki/Germany\#State_division)

The overall sample does not allow a direct comparison of Bavarian learners to North Rhine-Westphalian learners ${ }^{7}$. Nevertheless, the study lends itself to the testing of regional differences in German learner English, even if one of the regions is somewhat heterogeneous. The fact that the learners study English at two different universities might give some insight into how teaching methods influence the learners' linguistic progression during their studies.

Table 2-1 furthermore summarizes information about the speakers' sex, the learners' self-reported variety of English, and the amount of time spent in an English-speaking country. The informants are male (17 total) and female (23 total) to almost equal extents. Their self-reported varieties are mostly British English (BrE) and American English (AmE). Six students from the non-Bavarian group indicated that they speak a mixture of AmE and BrE, one student claims to have Australian English. In terms of "time spent abroad" the advanced students stayed in English-speaking countries for a considerably longer period than the beginners (an average of 9.8 month per person, as opposed to an average of 4.2 months). Within the "beginners" group, the non-Bavarians spent a noticeably longer average period of 5.8 months abroad, as opposed to 2.6 months for the non-Bavarians. The Bavarian beginners' time abroad even reduces to 0.8 months, if one student who spent one and a half years in the US is excluded. Bavarian and nonBavarian advanced students show a minor difference of 10.8 months as opposed to 8.8 months per person. The analysis below will test if a longer time of input of native English has an impact on pronunciation, which sounds intuitively correct but has not been tested on German learners.

\footnotetext{
${ }^{7}$ The aim for future studies is to compare groups of speakers from various federal states of Germany.
} 


\subsection{Methodology}

The informants were recorded at the universities of Regensburg and Cologne in the summer of 2009, using a high quality microphone and a digital voice recorder.

Learners were asked to read an English and a German word list (table 3-2) to obtain their most monitored pronunciation, which presumably resembles their respective target varieties most ${ }^{8}$. The lists are not restricted to the vowels under closer scrutiny here, but contain all stressed monophthongs of English and German. This procedure of basing the analysis on full vowel systems (1320 tokens) makes the relationship between vowel tokens highly reliable from an acoustical point of view.

The recordings were analysed in PRAAT 5 (Boersma and Weenink). Vowels were measured in the centre. In order to make female and male formant values comparable, they have been normalized using Eric Thomas's and Tyler Kendall's R-script on their NORM-website (Thomas \& Kendall 2007). Normalization follows Nearey's (1977) formulas, which have been evaluated as being very reliable when the full vowel spaces of the informants are available. (Thomas \& Kendall 2007; Tyler Kendall p.c.).

As indicated above, the present study is restricted to the following areas of vowel space:

- high front vowels (English BEAD, BID, German BIETEN, BITTEN)

- high back vowels (English BOOED, BUDDHIST, FOOD, FOOT, German TUTEN, TUSCH)

- low and mid front vowels (English BED, BAD, German BETEN, BÄTEN, KÄTZCHEN)

Table 3-2: English and German wordlists used for the experiment

\begin{tabular}{|c|c|c|c|c|c|}
\hline English Word & $\mathrm{X} \mathrm{SAMPA}^{9}$ & IPA & German Word & X-SAMPA & IPA \\
\hline BEAD & /i:/ & /i:/ & BIETEN & /i:/ & /i:/ \\
\hline BID & $/ \mathrm{I} /$ & $/ \mathrm{I} /$ & BITTEN & $/ \mathrm{I} /$ & $/ \mathrm{I} /$ \\
\hline BED & $/ \mathrm{e} /$ & $/ \mathrm{e} /$ & (TÜTE) & $/ \mathrm{y}: /$ & /y:/ \\
\hline BAD & $/\{/$ & $/ \mathfrak{l} /$ & (FÜTTERN) & $/ \mathrm{Y} /$ & $/ \mathrm{Y} /$ \\
\hline$(\mathrm{BARD})^{10}$ & /A:r/ & $/ \mathrm{a}: \mathrm{r} /$ & BETEN & /e:/ & /e:/ \\
\hline (PALM) & /A:/ & /a:/ & BETTEN & $/ \mathrm{E} /$ & $/ \varepsilon /$ \\
\hline (BATH) & $/ \mathrm{A}: \sim\{/$ & $/ \mathrm{d}: \sim æ /$ & BÄTEN & /E:/ & $/ \varepsilon: /$ \\
\hline (BODY) & /Q $\sim \mathrm{A}: /$ & $/ \mathrm{p} \sim \mathrm{a}: /$ & KÄTZCHEN & $/ \mathrm{E} /$ & $/ \varepsilon /$ \\
\hline (BAWD) & /O:/ & /o:/ & (HÖHLE) & /2:/ & /ø:/ \\
\hline$(\mathrm{COT})$ & /Q $\sim \mathrm{A}: /$ & $/ \mathfrak{p} \sim \mathrm{a}: /$ & (HÖLLE) & $/ 6 /$ & $/ œ /$ \\
\hline (CAUGHT) & /O:/ & /o:/ & TUTEN & /u:/ & /u:/ \\
\hline BUDDHIST & $/ \mathrm{U} /$ & $/ \mathrm{U} /$ & TUSCH & $/ \mathrm{U} /$ & $/ \mathrm{U} /$ \\
\hline BOOED & /u:/ & /u:/ & (BOTEN) & /o:/ & /o:/ \\
\hline
\end{tabular}

\footnotetext{
${ }^{8}$ It might be instructive to complement the present study by analysing a reading passage or free conversation in order to see if less monitored speech displays its own peculiarities.

${ }^{9}$ Using the X-SAMPA system instead of IPA symbols facilitates plotting in PRAAT.

${ }^{10}$ The words BARD and BIRD are representatives of potentially rhoticized vowels and an analysis of these might give insights into how consistent learners are in targeting their preferred variety (AmE or BrE). This, however, exceeds the scope of the present paper and will be treated elsewhere. (Kautzsch, in preparation b).
} 


\begin{tabular}{|l|l|l|l|l|l|}
\hline English Word & X-SAMPA & IPA & German Word & X-SAMPA & IPA \\
\hline FOOT & $/ \mathrm{U} /$ & $/ \mathrm{u} /$ & (SOCKEN) & /O/ & $/ \mathrm{o} /$ \\
\hline FOOD & $/ \mathrm{u} / /$ & $/ \mathrm{u}: /$ & (BATEN) & $/ \mathrm{A}: \sim \mathrm{a}: /$ & $/ \mathrm{a}: \sim \mathrm{a}: /$ \\
\hline (BUD) & $/ \mathrm{v} /$ & $/ \mathrm{s} /$ & (HATTEN) & $/ \mathrm{A} \sim \mathrm{a} /$ & $/ \mathrm{a} \sim \mathrm{a} /$ \\
\hline (BIRD) & $/ 3: /$ & $/ 3: /$ & & & \\
\hline
\end{tabular}

These data provide a very solid basis for testing how positive and negative transfer influence the acquisition of an L2 vowel system, if learners from different regional L1 backgrounds acquire English vowels in different ways, and if learners from different levels of expertise and with different amounts of exposure to native English display different stages of the acquisition process.

\section{Results}

The results are presented in three sections, one each dealing with the acoustic details of the three areas of vowel space under scrutiny here (4.1 to 4.3). Where applicable, English and German vowels are placed in the same graph in order to contrast students' vowel production in L1 and L2 directly and to visualize L1 transfer. As is common practice, the F1 and F2 axes in the plots are inverted so that vowels with a fronted value occur on the left and vowels with a lowered value appear at the bottom of the plot. As indicated above, the formant values in the graphs are normalized.

\subsection{High front vowels}

Both German and English have two high front vowels. The long vowels were elicited by the words BEAD and BIETEN, the short ones by BID and BITTEN, as shown in table 4-1.

Table 4-1: English and German high front vowels

\begin{tabular}{|l|l|l|l|l|l|}
\hline English & X-SAMPA & IPA & German & X-SAMPA & IPA \\
\hline BEAD & $/ \mathrm{i}: /$ & $/ \mathrm{i}: /$ & BIETEN & /i:/ & $/ \mathrm{i}: /$ \\
\hline BID & $/ \mathrm{I} /$ & $/ \mathrm{I} /$ & BITTEN & /I/ & $/ \mathrm{I} /$ \\
\hline
\end{tabular}

\subsubsection{BEAD vs. BIETEN}

In figures 4-1 and 4-2 the English BEAD-vowel is represented by "i:(e"11, German BIETEN occurs as "i:(g”.

\footnotetext{
${ }^{11}$ In the vowel plots it is necessary to distinguish between English and German versions of the respective vowels. When these are represented by the same symbol in the XSAMPA-system (i:, I, u:, U), "(e" and "(g" are added for "English" and "German", respectively.
} 


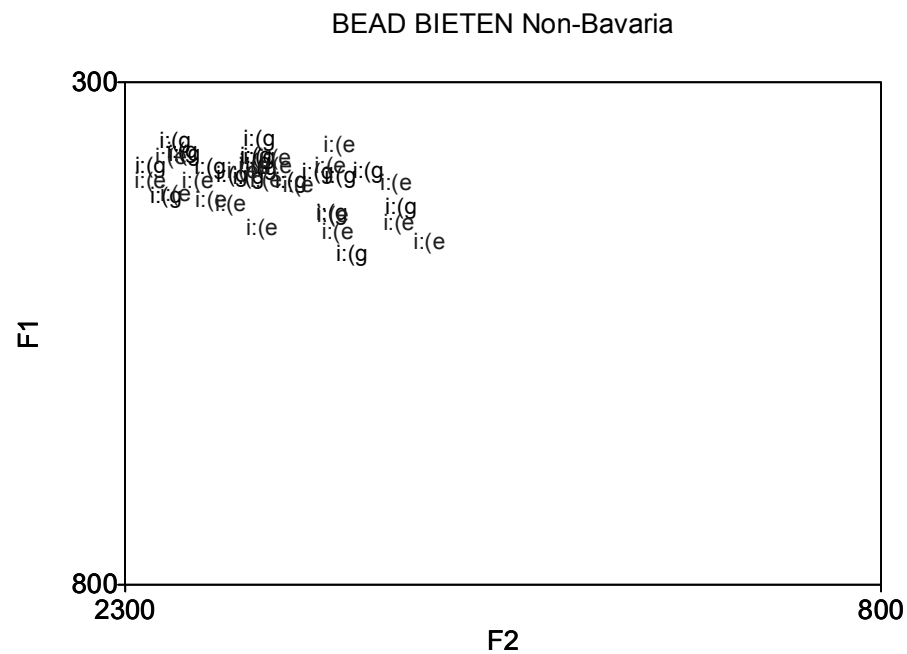

Figure 4-1: English and German long high front vowels of non-Bavarian learners

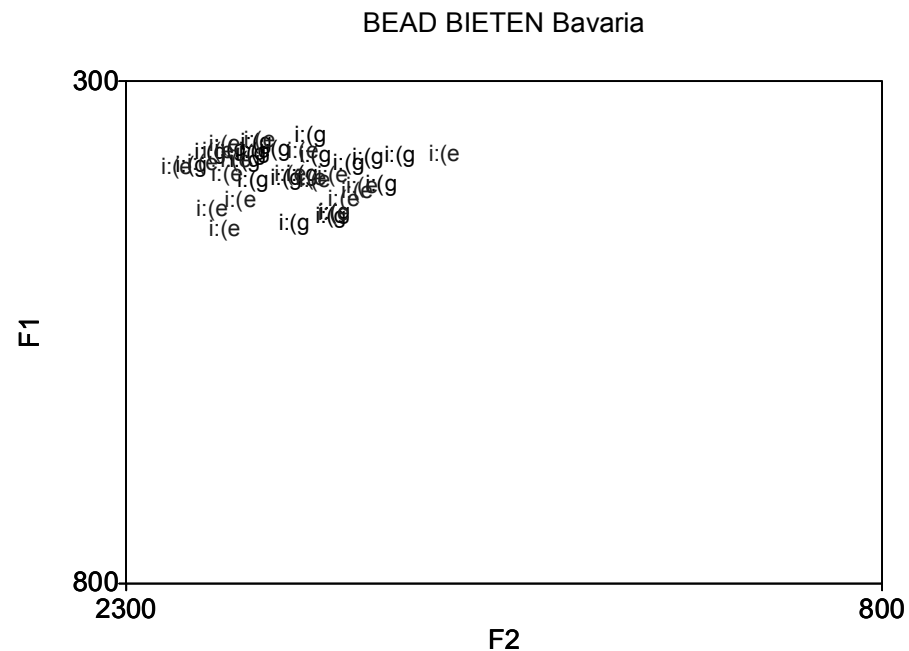

Figure 4-2: English and German long high front vowels of Bavarian learners

A comparison of the two plots shows that in both regional groups English and German /i:/ are produced in the same F1/F2 frequency ranges, which documents a clear cases of positive transfer for all learners. 


\subsubsection{BID vs. BITTEN}

In figures 4-3 and 4-4 English BID and German BITTEN are represented by the symbols "I(e" and "I(g", respectively.

Here we obtain the same results as with the long vowels: Most learners transfer their native vowels into English. In addition, both regional groups include slightly fronted tokens (cf. the circles in figures 4-3 and 4-4), all of which were produced by advanced students. Since the transfer of German /I/ to English would result in appropriate pronunciation, it is somewhat surprising that these advanced students deviate from their L1 vowels. One possible explanation is their desire to sound different from their L1.

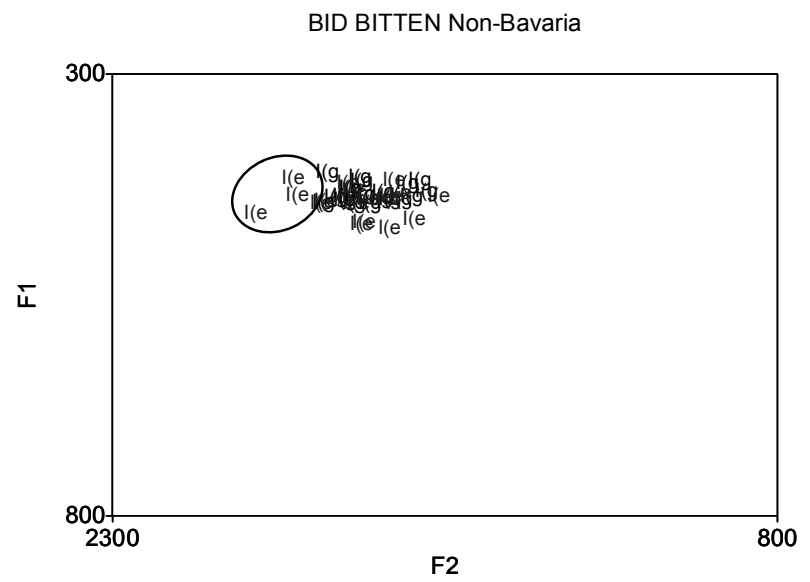

Figure 4-3: English and German short high front vowels of non-Bavarian learners

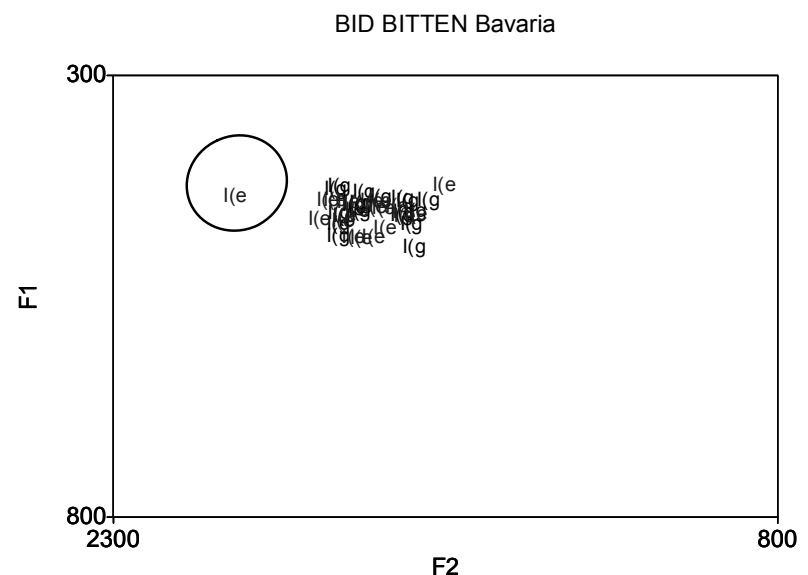

Figure 4-4: English and German short high front vowels of Bavarian learners 


\subsection{High back vowels}

Both German and English have two high back vowels, short $/ \mathrm{v} /$ and long /u:/. The German vowels were elicited using the words TUTEN and TUSCH. In order to support the auditory impression that the situation with high back vowels is more complex than with high front vowels, four words were used to elicit the English vowels: the less frequent words BOOED and BUDDHIST (as used in Ladefoged 2001) and the more frequent ones FOOD and FOOT (Table 4-2).

Table 4-2: English and German high back vowels

\begin{tabular}{|l|l|l|l|l|l|}
\hline English & X-SAMPA & IPA & German & X-SAMPA & IPA \\
\hline BUDDHIST & $/ \mathrm{U} /$ & $/ \mathrm{u} /$ & TUSCH & $/ \mathrm{U} /$ & $/ \mathrm{u} /$ \\
\hline FOOT & $/ \mathrm{U} /$ & $/ \mathrm{u} /$ & & & \\
\hline BOOED & $/ \mathrm{u}: /$ & $/ \mathrm{u}: /$ & TUTEN & $/ \mathrm{u}: /$ & $/ \mathrm{u}: /$ \\
\hline FOOD & $/ \mathrm{u}: /$ & $/ \mathrm{u}: /$ & & & \\
\hline
\end{tabular}

In order to understand the learners' production of high back vowels, it is necessary to contrast their regional varieties of German. To that end, table 4-3 lists the mean values for F1 and F2 by regional group and word. Vowel plots for FOOT vs. TUSCH and for FOOD vs. TUTEN will be provided below (4.2.1 and 4.2.2).

Table 4-3: F1 and F2 mean frequencies for English and German high back vowels in German learners

\begin{tabular}{|l|l|l|l|l|}
\hline & \multicolumn{2}{|l|}{ Bavaria } & \multicolumn{2}{l|}{ Non-Bavaria } \\
\hline Mean values & F1 $(\mathrm{Hz})$ & F2 $(\mathrm{Hz})$ & F1 $(\mathrm{Hz})$ & F2 $(\mathrm{Hz})$ \\
\hline FOOD & 425 & 1164 & 421 & 1248 \\
\hline BOOED & 413 & 1190 & 422 & 1235 \\
\hline TUTEN & 406 & 1105 & 406 & 1092 \\
\hline TUSCH & 468 & 1244 & 457 & 1179 \\
\hline FOOT & 475 & 1229 & 470 & 1262 \\
\hline BUDDHIST & 452 & 1256 & 446 & 1285 \\
\hline
\end{tabular}

A comparison of the F2 values for German TUTEN and TUSCH by region (cf. boxed cells in table 4-3) leads to the following observations. With /u:/ (TUTEN), the F2 frequencies are almost identical $(1105 \mathrm{~Hz}$ vs. $1092 \mathrm{~Hz})$ for Bavarians and non-Bavarians, which means that the L1 starting points for possible positive transfer are similar. On the contrary, the Bavarian speakers' versions of German / $/$ (TUSCH) are more front than in the non-Bavarians (cf. the larger F2 values for Bavarians as opposed to non-Bavarians, 
$1244 \mathrm{~Hz}$ vs. $1179 \mathrm{~Hz}$, respectively). Here the two groups have two different L1 starting points for possible transfer.

Turning to the mean values of the English vowels, it becomes apparent that, although positive transfer is in principle possible, it operates only to a limited extent. With Bavarian speakers positive transfer takes place in the case of $/ \mathrm{u} / \mathrm{cf}$. the minor differences between the F1 and F2 values for FOOT / BUDDHIST as opposed to TUSCH: $7 \mathrm{~Hz}$ and $-16 \mathrm{~Hz}$ for $\mathrm{F} 1,-15 \mathrm{~Hz}$ and $12 \mathrm{~Hz}$ for $\mathrm{F} 2$ ). On the other hand, the $\mathrm{F} 1$ and F2 values for FOOD and BOOED differ, albeit slightly, from the values for TUTEN $\left(14 \mathrm{~Hz}^{12}\right.$ and $7 \mathrm{~Hz}$ for $\mathrm{F} 1,59 \mathrm{~Hz}$ and $85 \mathrm{~Hz}$ for $\mathrm{F} 2$ ). This means that positive transfer does not take place in the case of /u:/; instead, Bavarian learners produce a somewhat fronted version. U-fronting is a well-known feature in some native varieties of English and to observe this in learners can be interpreted as an attempt to sound more native. The fact that Bavarian learners front /u:/ but do not front $/ \mathrm{v} /$ can also be an indicator of linguistic insecurity, with learners not knowing which target sound to aim at. However, it could also indicate that they perceive their native $/ \mathrm{U} /$ to be front enough, whereas they perceive their native /u:/ as too far back to sound English.

The non-Bavarian speakers transfer neither $/ \mathrm{v} /$ nor $/ \mathrm{u}: /$, but produce clearly fronted variants of both, which is reflected in the strong differences between German and English F2 values. FOOD and BOOED exceed TUTEN by $256 \mathrm{~Hz}$ and $243 \mathrm{~Hz}$, respectively. FOOT and BUDDHIST exceed TUSCH by $83 \mathrm{~Hz}$ and $106 \mathrm{~Hz}$. One explanation is that these learners, as the Bavarians in the case of $/ \mathrm{u}: /$, tend to imitate native varieties of English. In addition, it is also possible that they perceive their own high back vowels to be too far back and thus change them in an effort to sound less nonnative.

The second finding with non-Bavarians is that they front both $/ \mathrm{v} / \mathrm{and} / \mathrm{u}$ :/ to almost the same degree, which is documented by very similar F2 values between $1235 \mathrm{~Hz}$ and $1285 \mathrm{~Hz}$. In native varieties of English / $\mathrm{u} /$ is more front than /u:/. The exaggeration of the fronting of $/ \mathrm{u}$ :/ in non-Bavarian learners can again be interpreted as an indicator of insecurity about the target sound.

Taken together, non-Bavarian and Bavarian learners display some degree of insecurity in how to pronounce English high back vowels. The most likely reason for this is that the models they have, i.e. different varieties of English, are variable in their realisation of high back vowels.

\footnotetext{
${ }^{12}$ The value here is calculated by subtracting the English value from the German value. Negative values indicate that the German one is smaller than the English one.
} 


\subsubsection{FOOT vs. TUSCH}

In figures 4-5 and 4-6 the sounds produced in the words FOOT and TUSCH are plotted as "U2(e" and "U(g", respectively.

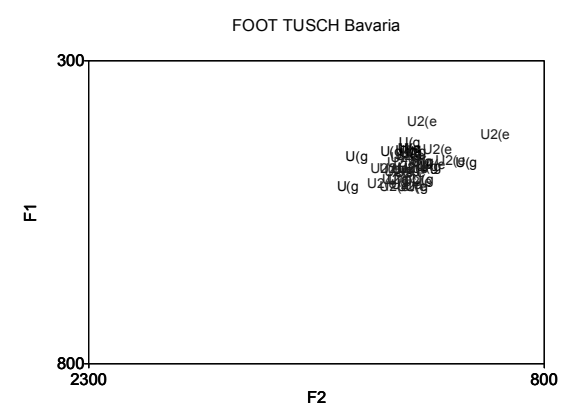

Figure 4-5: English and German short high back vowels of Bavarian learners

(FOOT vs. TUSCH)

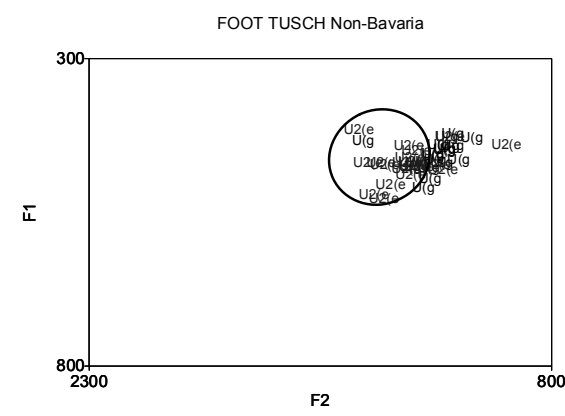

Figure 4-6: English and German short high back vowels of non-Bavarian learners (FOOT vs. TUSCH)

As mentioned above, the differences between the two regional groups are more salient than with high front vowels. The majority of the Bavarian learners (cf. the almost identical F1/F2 areas in figure 4-5) transfer their native sounds ${ }^{13}$. On the other hand, non-Bavarian learners (figure 4-6), beginners and advanced student alike, produce fronted versions of $/ \mathrm{u}$, although positive transfer would be possible (cf. the adjacent but different F1/F2 frequency spectra in figure 4-6, fronted / $\mathrm{s} / \mathrm{s}$ are marked by a circle).

One striking finding that could not be demonstrated on the basis of mean values is that both English and German / $\mathrm{s} / \mathrm{s}$ are fairly variable, the ones of non-Bavarian learners even more so. Thus in addition to the variability of the target varieties, variable starting points in the L1 are also an issue not be neglected when interpreting transfer.

\subsubsection{FOOD vs. TUTEN}

Long high back vowels, represented by English FOOD and German TUTEN ("u:(e" and " $\mathrm{u}$ :(g" in figures 4-7 and 4-8, respectively), deliver the same results as short back vowels: Bavarian learners transfer their native sounds (figure 4-7), whereas nonBavarian learners front, i.e. produce new sounds (figure 4-8, circle).

\footnotetext{
${ }^{13}$ The two English tokens that are higher and further back are mispronunciations of the word FOOT using a long vowel. The two fronted German tokens can be seen as idiosyncratic variants in the speakers L1.
} 


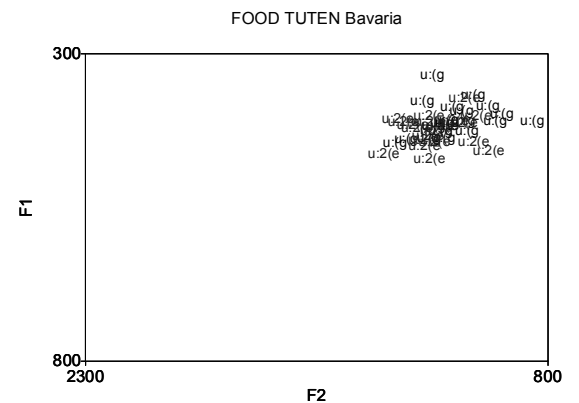

Figure 4-7: English and German long high back vowels of Bavarian learners

(FOOD vs. TUTEN)

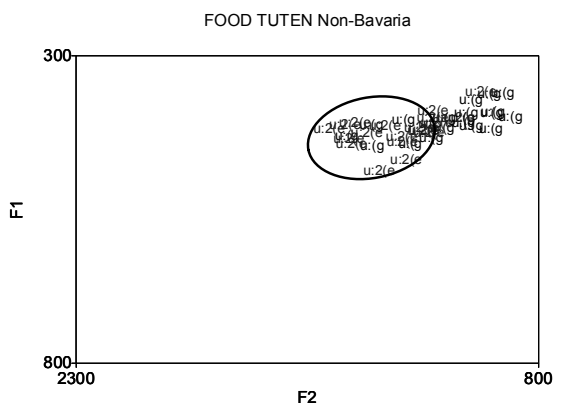

Figure 4-8: English and German long high back vowels of non-Bavarian learners (FOOD vs. TUTEN)

Peculiarities to be mentioned here are that the German and English long high back vowels of the two regional groups are spread over fairly different areas. Some nonBavarian learners have a fairly fronted German /u:/, while with Bavarian learners some tokens of English /u:/ are slightly lowered and some tokens of German /u:/ raised.

This mirrors the findings with short back vowels that learners' insecurity in the production of high back vowels has two sources: the variability in the varieties of English and variability in German. ${ }^{14}$

\subsection{Mid and low front vowels: the BED / BAD distinction}

The third group of vowels analyzed here are mid and low front vowels. The similarity between English and German is not as clear-cut as with high front and high back vowels. English has a mid front vowel /e/, represented in the word list by BED, and a low front vowel $/ \mathfrak{\Re} /$, represented by BAD. Both are short. German has two long vowels in this area and one short vowel (cf. table 4-4). The long ones are a high mid vowel /e:/ (also called half-close) and a low mid vowel $/ \varepsilon: /$ (also called half-open). The German long high mid vowel is represented by the word BETEN, the long low mid vowel by the word BÄTEN. The German short mid vowel $/ \varepsilon /$ is low mid in quality and is represented by BETTEN and KÄTZCHEN. Two words are used because German $/ \varepsilon /$ is orthographically represented by both $<\mathrm{e}>$ and $<\ddot{\mathrm{a}}>$.

Table 4-4: English and German non-high front vowels

\begin{tabular}{|l|l|l|l|l|l|}
\hline English & X-SAMPA & IPA & German & X-SAMPA & IPA \\
\hline BED & $/ \mathrm{e} /$ & $/ \mathrm{e} /$ & BETTEN & $/ \mathrm{E} /$ & $/ \varepsilon /$ \\
\hline BAD & $/\{/$ & $/ \mathfrak{a} /$ & KÄTZCHEN & $/ \mathrm{E} /$ & $/ \varepsilon /$ \\
\hline & & & BÄTEN & $/ \mathrm{E}: /$ & $/ \varepsilon: /$ \\
\hline & & & BETEN & $/ \mathrm{e}: /$ & $/ \mathrm{e}: /$ \\
\hline
\end{tabular}

\footnotetext{
${ }^{14}$ A promising follow-up study would be to test these results using an increased number of informants focussing on their idiolects.
} 


\subsubsection{BED / BAD in German learners}

In order to tackle the question if German learners make a distinction between BED (/e/, represented as "e") and BAD (/æ/, represented as "\{"), at all, figures 4-9 to 4-12 plot the English vowels by region and proficiency group.

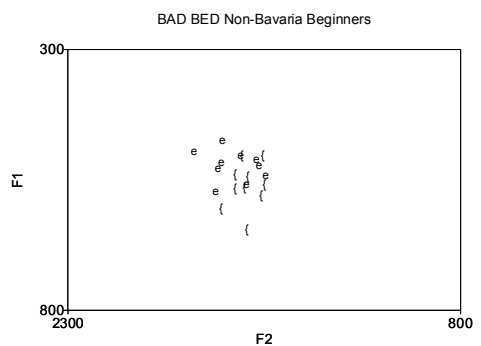

Figure 4-9: BED and BAD in nonBavarian beginners

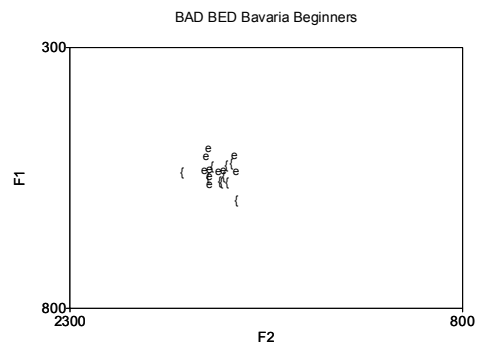

Figure 4-11: BED and BAD in Bavarian beginners

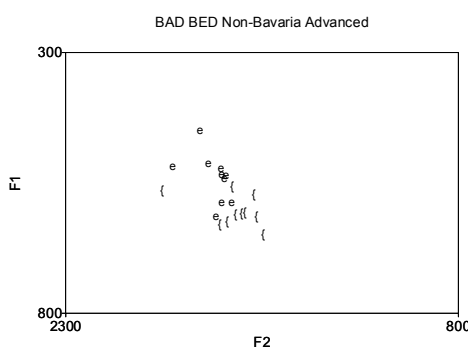

Figure 4-10: BED and BAD in nonBavarian advanced learners

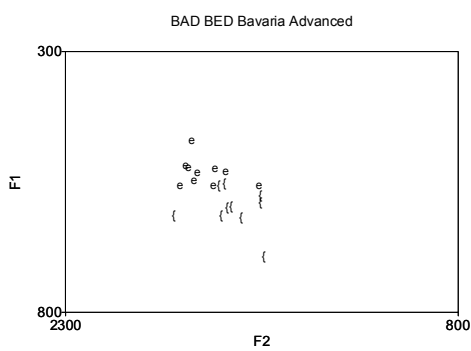

Figure 4-12: BED and BAD in Bavarian advanced learners

Three observations can be made. First, both regional groups display differences between beginners and advanced students. Beginners produce /e/ and /æ/ ("e" and " $\{"$ in the figures) in overlapping mostly mid front areas of vowel space (figures 4-9 and 4-11). Advanced students (figures 4-10 and 4-12) do so in less overlapping areas, with /æ/ ("\{") expanding towards the low front region. To make this clearer, table 4-5 lists the mean values for $\mathrm{F} 1$ and $\mathrm{F} 2$.

Table 4-5: F1 and F2 mean frequencies for BAD/BED in German learners

\begin{tabular}{|l|l|l|l|l|}
\hline & \multicolumn{2}{|l|}{ BED } & \multicolumn{2}{l|}{ BAD } \\
\hline & F1 (Hz) & F2 (Hz) & F1 (Hz) & F2 (Hz) \\
\hline Bavaria Beginners & 530 & 1742 & 548 & 1730 \\
\hline Bavaria Advanced & 532 & 1766 & 601 & 1663 \\
\hline Non-Bavaria Beginners & 522 & 1666 & 561 & 1620 \\
\hline Non-Bavaria Advanced & 540 & 1732 & 603 & 1659 \\
\hline
\end{tabular}


A comparison of the F1 mean values (cf. the shaded cells in table 4-5), which increase as the vowel becomes lower, shows that F1 values are almost identical for the Bavarian beginners (BED: 530 vs. BAD: 548), in proximity to each other for the non-Bavarian beginners (BED: 522 vs. BAD: 561), and in considerably distance of each other for the two advanced groups (Bavaria advanced: BED: 532 vs. BAD: 601; non-Bavaria advanced: BED: 540 vs. BAD: 603). This leads to observations two and three, namely that non-Bavarian beginners have a clearer BED/BAD distinction than Bavarian beginners (cf. figures 4-9 and 4-11 and table 4-5), and that the two advanced groups are very similar in their BED/BAD distinctions (cf. figures 4-10 and 4-12 and table 4-5).

Taken together, the BED/BAD distinction becomes more prominent as proficiency increases. The Bavarian students seem to develop this distinction only during their studies, while the non-Bavarian students at least partly distinguish already at the beginning of their studies.

\subsubsection{BED / BAD vs. BETTEN / KÄTZCHEN / BETEN / BÄTEN}

This section compares German and English mid and low front vowels. To that end, figures 4-13 and 4-14 first survey German mid and low front vowels in the two regional

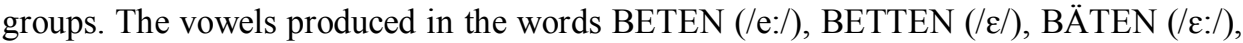
and KÄTZCHEN (/ع/) are represented in the figures by "e:", "E1", "E:", and "E2", respectively.

What can be gleaned from the figures is that in both groups /e:/ (BETEN) is

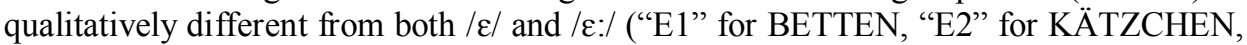
"E:" for BÄTEN) ${ }^{15}$. The latter two only differ in quantity, covering approximately the same $F 1 / F 2$ frequency ranges.

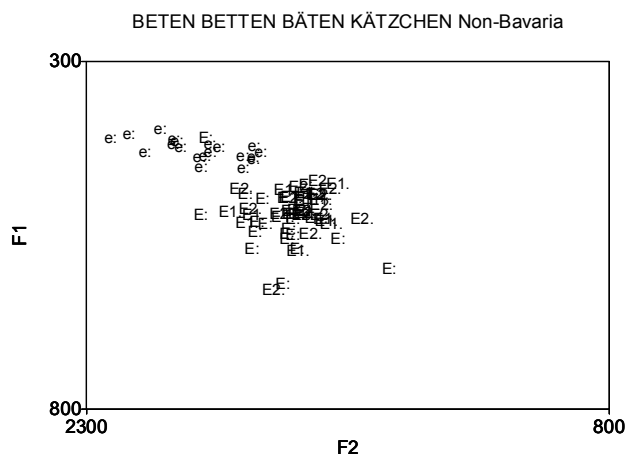

Figure 4-13: German non-high vowels in non-Bavarian learners

\footnotetext{
${ }^{15}$ One speaker produces /e:/ for both BETEN and BÄTEN (“E:" plotted in the "e:" area in figure 413). Phonologically, this is a simplification of the German system, where generally one long vowel is paired with one short vowel. In analogy to this, German /ع:/ is at times replaced by /e:/. This tendency is strong in spoken German but doesn't surface in the present data due to the high degree of monitoring.
} 


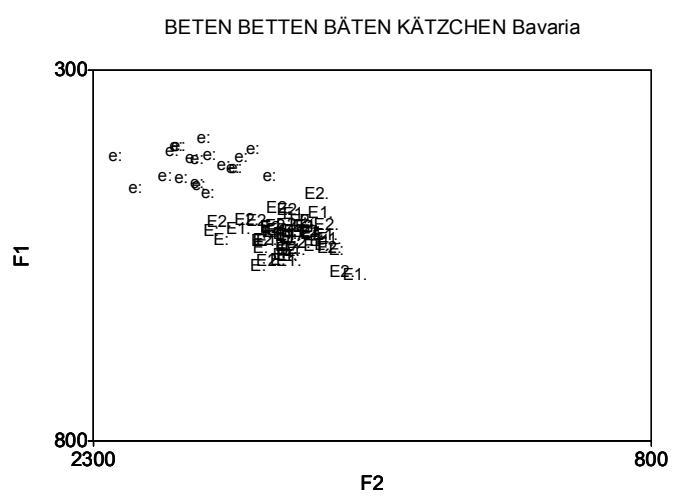

Figure 4-14: German non-high front vowels in Bavarian learners

Thus, all German learners in this sample have two qualitatively different vowels which they could transfer to English BED and BAD, respectively. The regional differences here are very marginal indeed, with non-Bavarian speakers covering a slightly wider area with $/ \varepsilon /$ and $/ \varepsilon: /$.

As in the preceding chapters, figures 4-15 to 4-18 contrast the English and German vowels by group and proficiency level in order to show in which cases and along which lines L1 transfer takes place. What becomes apparent immediately is that the learners do not transfer the contrast of the German long vowels /e:/-/ $\varepsilon: /$. None of the vowels produced in BED or BAD are located in the German BETEN area on the upper left side of figures 4-15 to 4-18.

Bavarian beginners (figure 4-15) have all instances of BAD and BED within the realm of BÄTEN / BETTEN / KÄTZCHEN. This means they transfer German / $/$ / to both $\mathrm{BED}$ and $\mathrm{BAD}$, i.e. positive transfer in the first case, negative transfer in the second.

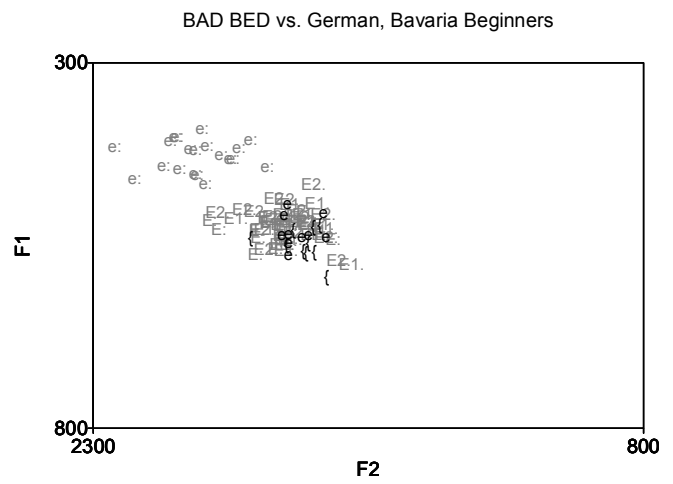

Figure 4-15: $\mathrm{BAD}, \mathrm{BED}$ and German mid and low front vowels in Bavarian beginners 
The same holds for non-Bavarian beginners (figure 4-16). Three of them, however, produce lower versions of BAD ("\{") outside their native F1/F2 range (figure 4-16). Thus, besides positive and negative transfer, some learners do not transfer their native sounds but have acquired a new sound (cf. the circle in figure 4-16).

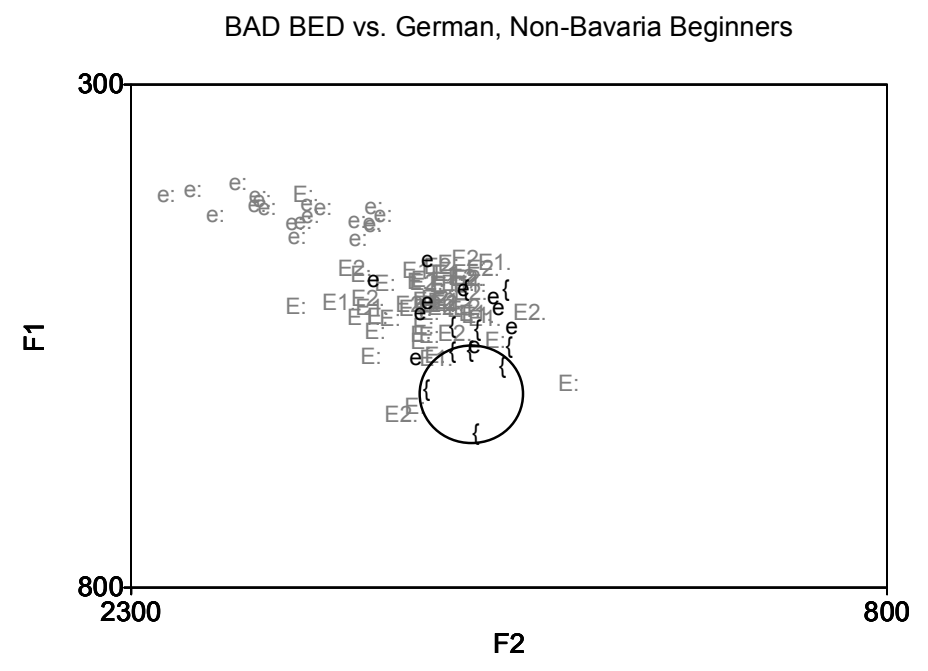

Figure 4-16: BAD, BED and German non-high front vowels in non-Bavarian beginners

In the two advanced groups almost all instances of BAD lie outside the BED area (cf. circles in figures 4-17 and 4-18).

BAD BED vs. German, Bavaria Advanced

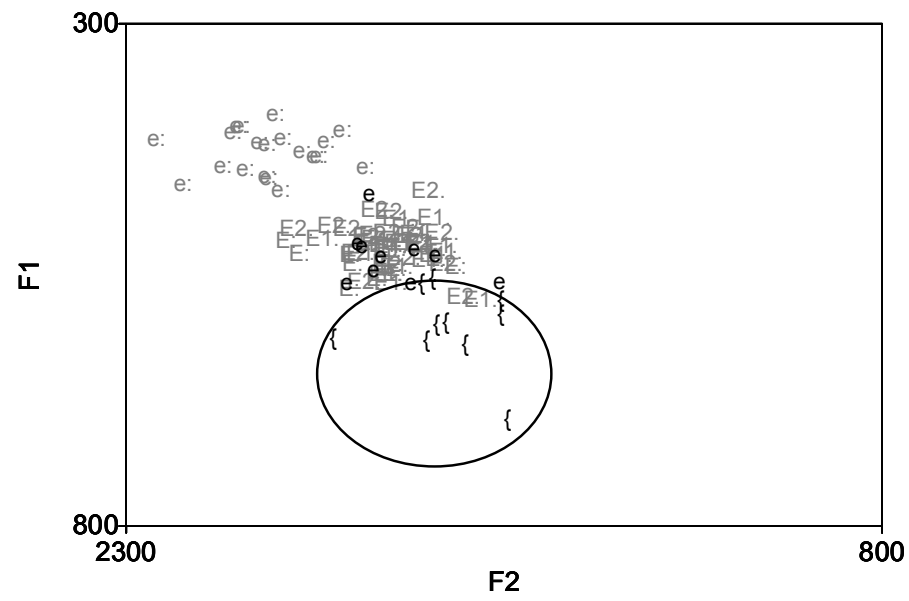

Figure 4-17: BAD, BED and German non-high front vowels in Bavarian advanced learners 
This means that advanced students have acquired a new sound in the case of BAD. Interestingly, there is also a slight difference between Bavarian and non-Bavarian advanced students: It is with the former that the contrast between BED and BAD is more prominent. (Compare the circled vowels in figures 4-17 and 4-18).

BAD BED vs. German, Non-Bavaria Advanced

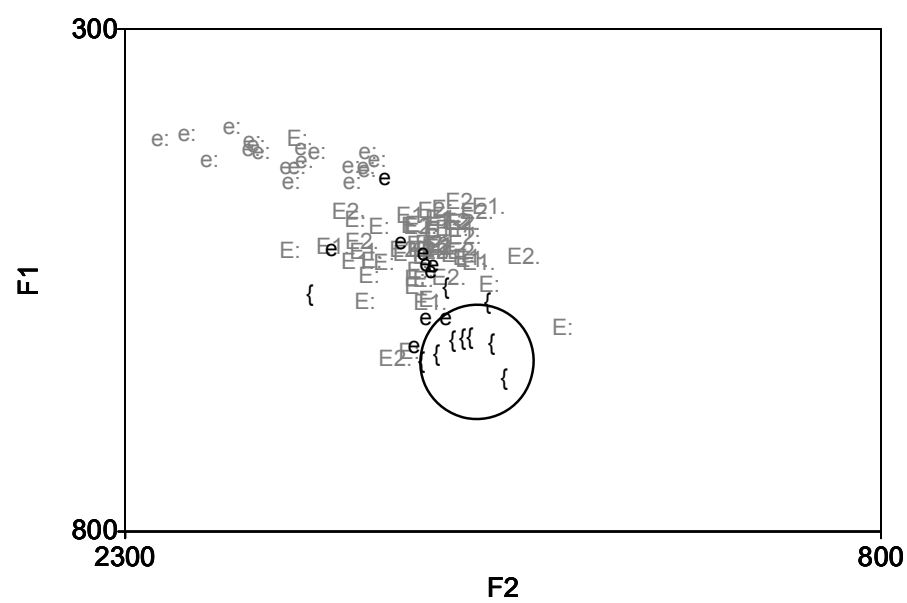

Figure 4-18: BAD, BED and German non-high front vowels in non-Bavarian advanced learners

All in all, BED and BAD become more distinct with increasing proficiency. The two regional groups, however, proceed in different ways. The non-Bavarian beginners have a more advanced starting point than the Bavarian beginners. This early ability to distinguish between $\mathrm{BED}$ and $\mathrm{BAD}$ is probably the result of considerably more experience in an English speaking country and therefore more native English input, as shown in table 3-1 above. On the other hand, non-Bavarian learners make less relative progress from the beginners' to the advanced level. Their BED/BAD distinction at an advanced level is not more clear-cut than the one of Bavarian advanced students. Nevertheless, both groups still display some minor overlap between BED and BAD (cf. the " $\{$ " items outside the circles in figures 4-17 and 4-18).

The Bavarians relatively swift progress from no distinction to a comparatively clear distinction can be explained by the relatively high amount of input they have received. The advanced students spent a considerable time abroad (cf. table 3-1 above) and were exposed to a fairly high amount of formal instruction, including pronunciation tests and practical phonetics, at the University of Regensburg. In contrast, non-Bavarian students also spent considerable time in an English-speaking country, but language instruction is of a different nature at the University of Cologne, where students have less direct pronunciation instruction and probably proceed from the beginners' level to the advanced level in a rather immersive way. 


\section{Discussion}

This section pulls together the main results presented above and interprets them in the light of positive and negative transfer. In addition, it will aim at explaining learnerinternal variability.

In the case of high front vowels positive transfer from the students' L1 leads to acceptable results in English. This is why most instances of English /i:/ and / $/$ / fall into the same F1/F2 frequency range as German /i:/ and /I/. In some cases, advanced students produce a fronted version, which could be an indicator for a subconscious desire to make their English sound different from their German.

With high back vowels, the situation is different. Bavarian students in both proficiency groups show positive transfer with $/ \mathrm{u} /$, but produce a slightly fronted version of $/ \mathrm{u}$ :/. Non-Bavarian students, on the contrary, do not transfer, but front both $/ \mathrm{v} / \mathrm{cnd}$ /u:/. Moreover, they do this to such an extent that their L2 English / $/ / \mathrm{s}$ and $/ \mathrm{u}: / \mathrm{s}$, in contrast to native English, are almost equally fronted. The interpretation of these findings is threefold. First, the reason for fronting in both regional groups might reflect a tendency to sound different from the L1 by approximating varieties of English in which $\mathrm{u}$-fronting is a regular feature. Second, the fact that non-Bavarians front to a larger degree than Bavarians could result from slight differences in the regional L1s, where the non-Bavarian high back vowels are further back than the Bavarian ones. Thus, nonBavarian learners might subconsciously interpret the possible transfer of their German vowels as negative or inappropriate and produce new ones. Third, and most plausibly, the variability of high back vowels within German as well as across varieties of English leads to insecurity about the target sounds, and results in the production of high back vowels in a wide frequency spectrum.

With respect to the BAD/BED distinction, transfer works along the following lines. The long mid front vowels of German (/e:/ and / $\varepsilon: /)$ are not used as the bases of transfer to English /e/-/æ/, although this would leave the contrast between the two vowels intact. It seems that these long vowels are, from the point of view of perception, too different from the English short vowels. Therefore, German learners either transfer the German short mid front vowel $/ \varepsilon /$ to both English contexts (positive transfer of $/ \varepsilon /$ to BED, negative transfer of $/ \varepsilon /$ to BAD), or they acquire a new sound /æ/, largely depending on their proficiency level. Bavarian beginners use German $/ \varepsilon /$ in both contexts, which results in BED and BAD being (near-)homophones. This is in fact a feature of a relatively early stage of acquisition - despite a minimum of seven years of learning and might hint at the fact that these learners do not perceive the distinction. The explanation for this might be their relatively low amount of time spent abroad and therefore their little experience with native English.

Non-Bavarian beginners largely use German $/ \varepsilon /$ in BED, i.e. positive transfer. In contrast to the Bavarian beginners, however, they have partly acquired a new sound $/ æ /$, possibly due to their higher amount of time spent in an English-speaking country and thus, as compared to the Bavarian beginners, their greater experience with native English.

The two groups of advanced students have spent an even greater amount of time in an English-speaking country, and therefore it does not come as a surprise that learners in 
these groups differentiate between BED and BAD highly systematically, largely using German / $/$ / in BED (positive transfer) and the acquired vowel /æ/ in BAD.

In addition to these differences due to proficiency, some differences within each regional group materialize when comparing the beginners to the advanced students: Bavarian learners seem to acquire the new sound /æ/ at a higher rate than the nonBavarians do. The two advanced groups are at a similar level, although the Bavarian learners start to differentiate between BED and BAD only during their studies, while the non-Bavarian learners already partly distinguish between BED and BAD at the beginning of their studies. In other words, the non-Bavarians do not take advantage of their lead. Having a closer look at the advanced students it even seems to turn out that the Bavarians are more consistent in their distinction between BED and BAD than the non-Bavarians. Taking into account that both advanced groups have spent a similar amount of time abroad, a likely factor that has helped speed up the Bavarians' swift progress is the type of instruction at the two universities. At Regensburg, students are required to do many language practice classes, most relevant here being theoretical and practical phonetics and phonology, as well as a pronunciation test and, in severe cases, remedial language lab practice. At Cologne, on the other hand, students rather focus on research classes and only do a minimum of language practice with focus on grammar and translation, as well as some theoretical phonetics. Formal instruction may therefore minimize the initial disadvantage of little experience with native English in terms of pronunciation and help students acquire new sounds more efficiently.

\section{Conclusion}

The present paper has provided a cross-linguistic analysis of three areas of the German and English vowel inventories. It has shown that transfer is one of the main factors that influence the acquisition of L2 pronunciation.

However, the data taken from two groups of learners with two differing levels of proficiency and from two different German regions display some degree of variability and imply that transfer, positive as well as negative, is influenced by other factors. In the case of high front vowels, transfer does not take place in some advanced students who might want to sound different from their L1. As regards high back vowels, students variably transfer L1 sounds to L2 sounds, displaying some amount of insecurity which results from variability in both $\mathrm{L} 1$ and $\mathrm{L} 2$. With respect to the $\mathrm{BED} / \mathrm{BAD}$ distinction, negative transfer decreases as proficiency increases. Especially on the basis of the latter example, it could be demonstrated that the reduction of negative transfer is a result of increased exposure to native English both in natural contexts and in the classroom, with formal instruction playing a crucial role in speeding up the acquisition process.

In terms of future research, it might be beneficial to add further factors to the analysis (like, for example, a more detailed account of perception, the age of onset of language acquisition, motivation for learning English, or aptitude), expand the database in terms of features as well as informants, and go into the details of idiolects. 


\section{References}

Boersma, P. and D. Weenink. PRAAT. Doing phonetics by computer. [http://praat.org]

Eckmann, F. 1977. "Markedness and the Contrastive Analysis Hypothesis." Language Learning 27: 315-330.

Ellis, R. 1985. Understanding Second Language Acquisition. Oxford: OUP.

Flege J. E. and J. Hillenbrand. 1984. "Limits on phonetic accuracy in foreign language speech production." Journal of the Acoustic Society of America 76,3: 708-721.

Gut, U. 2009. Non-native Speech. A Corpus-based Analysis of Phonological and Phonetic Properties of L2 English and German. Frankfurt/Main et al.: Peter Lang.

Jenkins, J. 2000. The Phonology of English as an International Language. Oxford: OUP.

Jenkins, J. 2007. English as a Lingua Franca: Attitude and Identity. Oxford: Oxford University Press.

Kachru, B. B. 1985. "Standards, codification and sociolinguistic realism: the English language in the outer circle". In Quirk. R. and H. G. Widdowson (eds.), English in the World: Teaching and Learning the Language and Literatures. Cambridge: CUP.

Kachru, B. B. 1990. The Alchemy of English: The Spread, Functions, and Models of Non-Native Englishes. Urbana: Univ. of Illinois Press.

Kautzsch, A. In preparation a. "Oh what a mess! The acquisition of English low back vowels, mid back vowels and low central vowels by German learners."

Kautzsch, A. In preparation b. "Rhoticity in German learners of English". Paper proposed for the $16^{\text {th }}$ annual conference of the International Association of World Englishes (IAWE), Vancouver, Canada, 25-27 July 2010.

Kortmann, B. 2005. "Chapter V: Contrastive Linguistics: English and German". In Kortmann, B. 2005. Linguistics: Essentials. Berlin: Cornelsen, 156-191

Ladefoged, P. 2001. Vowels and Consonants. Second edition. Malden, MA et al.: Blackwell.

Lado, R. 1957. Linguistics Across Cultures. Ann Arbor: University of Michigan Press.

Major, R. C. 1987. "A model for interlanguage phonology." In Ioup, G. and S. H. Weinberger (eds.), Interlanguage Phonology. Cambridge, Massachusetts: Newbury House, 101-124.

Nearey, T. M. 1977. Phonetic Feature Systems for Vowels. Dissertation, University of Alberta. Reprinted 1978 by the Indiana University Linguistics Club

Odlin, T. 1989. Language Transfer. Cross-linguistic Influence in Language Learning. Cambridge: CUP.

Schachter, J. 1983. "A new account of language transfer." In Gass, S. M. and L. Selinker (eds.), Language Transfer in Language Learning. Rowley, Massachusetts: Newbury House.

Seidlhofer, B. 2007. "English as a lingua franca and communities of practice". In VolkBirke, S. and J. Lippert (eds.), Anglistentag 2006 Halle Proceedings. Trier: Wissenschaftlicher Verlag Trier, 307-318.

Thomas, E. R. and T. Kendall. 2007. NORM: The vowel normalization and plotting suite.

[http://ncslaap.lib.ncsu.edu/tools/norm/] 